\title{
Estudo morfossintático na região Norte de Mato Grosso/Brasil: usos de eu e mim
}

Morphosynthetic study in the North region of Mato Grosso/Brazil: uses of I and me

Neusa Inês PHILIPPSEN*

Universidade do Estado de Mato Grosso (UNEMAT)

RESUMO: Neste artigo, que se fundamenta nos princípios da Dialetologia Pluridimensional e Relacional (RADTKE; THUN, 1996), propusemo-nos a refletir sobre os usos pronominais em quatro cidades do Norte mato-grossense (Vera, Santa Carmem, Sinop e Cláudia), assim como em duas instituições de ensino, a Universidade do Estado de Mato de Mato (UNEMAT) e a Escola Estadual Nossa Senhora da Glória. Para tanto, utilizamo-nos de recursos teóricometodológicos que permitiram que documentássemos os pronomes $e u$ e mim utilizados nesses espaços em análise, com destaque ao olhar apurado que lançamos às dimensões diatópica, diafásica, diastrática, diagenérica e diassexual. Os resultados apreendidos foram transpostos a tabelas, quadros e cartogramas, na sequência, tecemos considerações analíticas sobre as preferências pronominais efetuadas no Norte de Mato Grosso, que mostraram um maior uso do pronome pessoal oblíquo mim antes de verbo no infinitivo.

PALAVRAS-CHAVE: Dialetologia. Pluridimensional. Pronomes. Norte de Mato Grosso.

ABSTRACT: In this article, which is based on the principles of Pluridimensional and Relational Dialectology (RADTKE e THUN, 1996), we propose to reflect on the pronominal uses in four cities from the north region of Mato Grosso state (Vera, Santa Carmem, Sinop and Cláudia) as well as in two teaching institutions: the University of Mato Grosso state (UNEMAT) and the state school Nossa Senhora da Glória. Therefore, we used theoreticalmethodological resources that allowed us to document the pronouns $I$ and $m e$ which are being used in these spaces under analysis, highlighting the accurate look that we launched to the diatopic, diaphasic, diastratic, diageneric and diassexual dimensions. The seized results were transposed to tables, charts and cartograms. In sequence, we made analytical considerations

\footnotetext{
* Pós-doutora pela Universidade de São Paulo (USP). Professora adjunta da Universidade do Estado de Mato Grosso. Tem experiência nas áreas de Letras/Linguística, com ênfase em Sociolinguística/Geolinguística, Linguística Aplicada e Língua Portuguesa/Diacronia. E-mail: neinph@yahoo.com.br
} 
about the pronominal preferences used in the north of Mato Grosso, which showed a greater use of the personal pronoun oblique $m e$ before the verb in the infinitive.

KEYWORDS: Dialectology. Pluridimension. Pronouns. North of Mato Grosso.

\section{Introdução}

Este artigo, que tem como propósito fundamental mostrar os usos pronominais de mim e eu que se efetuam no Norte de Mato Grosso/Brasil, congrega, como lócus, quatro cidades do norte mato-grossense - Vera, Santa Carmem, Sinop e Cláudia -, assim como duas instituições de ensino localizadas em Sinop, a Universidade do Estado de Mato de Mato (UNEMAT) e a Escola Estadual Nossa Senhora da Glória, espaços nos quais lançamos olhar aos empregos pronominais realizados por três faixas etárias distintas, acima de 50 anos, de 18 a 40 anos e de 13 a 15 anos. Denominamos nossos informantes mais velhos (acima de 50 anos) como pioneiros e os demais como estudantes.

Cabe ressaltarmos que esta pesquisa, que se fundamentou na Dialetologia Pluridimensional e Relacional (RADTKE; THUN, 1996), tem o intuito de contribuir com os estudos de abordagens dialetológicas, de gramática em uso e com o ensinoaprendizagem tanto do português local quanto do português brasileiro. Os principais teóricos mobilizados neste estudo são: Thun (2005), Coseriu (1979, 1992), Philippsen (2013) e Bagno (2007, 2011).

Mobilizamos, como principais recortes metodológicos, as dimensões diatópica, diastrática, diafásica, diagenérica e diassexual, as quais guiaram todo o percurso da pesquisa, desde a ida a campo, a aplicação do Questionário Morfossintático (QMS) do Projeto Atlas Linguístico do Brasil (Projeto ALiB), a seleção dos corpora e as tessituras analíticas.

Compreendemos, assim, que a importância desta investigação está além do olhar à constituição do falar local, mas, fundamentalmente, no registro científico deste falar que se junta aos estudos brasileiros da área, em especial por ser esta porção amazônica do território brasileiro em estudo recém-constituída, ou seja, surgida nos 1970, com a 
vinda, inicialmente, de (i)migrantes da região Sul do Brasil, tal como relata Philippsen (2013) em escritos sobre a História regional.

\section{Considerações teórico-metodológicas da pesquisa}

A Dialetologia Pluridimensional e Relacional, que foi desenvolvida pelos pesquisadores alemães Edgar Radtke e Harald Thun (1996), da Universidade de Kiel (Alemanha), na segunda metade do século XX, tem como propósito mesclar modelos teórico-metodológicos distintos, mas que se complementam e ampliam as possibilidades dos estudos de variação. Para tanto, importa coadunarem-se aos fatores diatópicos e linguísticos os extralinguísticos, ou seja, os olhares analíticos dos dialetólogos devem voltar-se tanto às variedades regionais quanto às sociais.

Observa-se, contudo, que novos campos de atuação passaram a interessar contemporaneamente aos estudos dialetológicos. As dimensões incorporadas à Dialetologia são diversas, tais como: a idade (dimensão diageracional), o sexo (dimensão diassexual), a escolaridade (dimensão diastrática), o estilo de fala (dimensão diafásica), o grupo social (dimensão diagrupal), a língua de contato (dimensão dialingual), a identidade social (dimensão diarreferencial).

Com relação à pluridimensionalidade, princípio que fundamenta o modelo teórico em questão, Thun (2005) apresenta dimensões e parâmetros que devem ser considerados em um estudo multidimensional:

1. Dimensão dialingual: aborda os contatos entre línguas ou variedades envolvidas no estudo.

2. Dimensão diatópica: reporta-se à descrição dos dados coletados nos diversos pontos de coleta, com destaque à dimensão diatópico-cinética, cujos parâmetros de análise podem ser topostáticos ou topodinâmicos. O primeiro refere-se a informantes demograficamente estáveis, enquanto o segundo se ocupa com os informantes em situação de migração.

3. Dimensão diastrática: considera a classe social e seus distintos estratos sociais, que seriam determinados pela escolaridade.

4. Dimensão diageracional: relacionada a duas ou mais faixas etárias (jovens, idade adulta, idosos); geralmente constitui-se pela geração II (GII) composta por 
falantes com mais de 55 anos de idade e pela geração I (GI) com falantes entre 18 e 36 anos de idade.

5. Dimensão diassexual: também conhecida como diagenérica, refere-se ao sexo/gênero, marcando a variação na fala entre homens e mulheres.

6. Dimensão diafásica: é também denominada como variação estilística, reporta-se às distintas formas estilísticas de se empreender a coleta de dados, que pode ser feita por meio de leitura, respostas ao questionário e conversa dirigida ou livre.

7. Dimensão diarreferencial: relacionada a questões objetivas e/ou metalinguísticas da língua.

8. Dimensão diarreligiosa: verifica a relevância do credo religioso no uso de uma determinada língua ou variedade.

Foi, portanto, este modelo de análise que fundamentou e direcionou nossa pesquisa, que se ateve ao nível morfossintático. As dimensões observadas, além da diatópica, foram a diageracional (idade), a diassexual (sexo/gênero), a diastrática (escolaridade) e a diafásica (respostas ao questionário e narrativas livres).

\section{1 aspecto morfossintático da língua e o recorte pronominal}

É possível afirmar que a morfossintaxe é responsável pela coesão relacionada à gramática e à ordem gramatical escolhida pelo autor, isto é, pela lógica do texto. Dessa forma, a estrutura gramatical escolhida facilitará o entendimento do leitor. Sendo assim, ambas, morfologia e sintaxe, constituem-se como níveis de descrição linguística que têm a incumbência de permitir alcançarmos a competência discursiva ou textual no âmbito da palavra e da oração ou da frase (morfossintaticamente), ou seja, de acordo com Coseriu (1992), de alcançarmos o saber expressivo para construirmos textos em situações determinadas.

Para este estudo, elegemos o aspecto morfossintático da língua para compreendermos como o estado de construção morfossintática se evidencia na região norte mato-grossense, mais especificamente em situações concretas de uso dos informantes de pesquisa, apreendidas nas narrativas livres e nas respostas às questões do Questionário Morfossintático (QMS) do ALiB. 
Eleito o aspecto morfossintático como objeto central deste trabalho foi-nos necessário, ainda, fazer um recorte mais específico, ou seja, das classes gramaticais abordadas pelo ALiB no QMS, escolhemos apenas o pronome, para o qual são dedicadas dez questões (23 a 32), nas quais se abordam possibilidades de variáveis para os pronomes pessoais, com ou sem preposição, os pronomes possessivos e indefinidos.

Essas variáveis, por sua vez, são impulsionadas por fatores condicionadores, sejam eles linguísticos ou sociais. Neste artigo, por causa da limitação de espaço, apresentamos apenas os resultados analíticos da questão $23^{1}$.

Cabe também ressaltarmos que, conforme Ilari e Basso (2006), a classe dos pronomes, como a dos advérbios, destaca-se como extremamente heterogênea. Para procurarem lidar com o 'problema' da heterogeneidade, manifesto com maior ênfase pela língua falada, gramáticas e gramáticos criaram várias subclasses distintas de pronomes: os pessoais, os possessivos, os demonstrativos, os relativos e os indefinidos.

Neste recorte, damos ênfase apenas ao pronome pessoal $e u$ e seu consequente pronome oblíquo tônico mim em seus (in)distintos usos antes de verbos no infinitivo. Nesse contexto, ressaltamos a compreensão de mudanças em consonância com Bagno, para o qual

\footnotetext{
as palavras não estão presas de uma vez por todas na classe em que surgiram. Muito pelo contrário, os casos de migração é que são regra - são poucas as palavras que só admitem uma única classificação, já que a maioria delas está sujeita aos processos de reanálise, metáfora, metonímia etc., que ativam a gramaticalização e a discursivação. (BAGNO, 2011, p. 829).
}

As mudanças, dessa forma, acontecem em todas as classes de palavras e são elas, portanto, a 'regra' e não a 'exceção'. No sequente subtópico, será feita a exposição analítica dos resultados alcançados.

\section{Procedimentos metodológicos e de análise: resultados da pesquisa}

Antes de iniciarmos os procedimentos de análise, confeccionamos tabelas, quadros, gráficos e cartogramas. Compreendemos essas etapas como imprescindíveis, não só para a apuração dos resultados da pesquisa, mas também por causa da

\footnotetext{
${ }^{1}$ Alguém pede para vocêlo(a)senhor(a) fazer uma tarefa. Mas outra pessoa acha que a tarefa era para ela. Então, vocêlo(a)senhor(a) diz: Essa tarefa, na verdade, é para fazer.

Recebido em 02/08/2019 
necessidade de apreender o "processo dinâmico", fundamentalmente a partir de considerações sobre o caráter particular de uso das variantes pronominais presentes ou não na fala dos informantes das quatro cidades em foco e das duas instituições de ensino que integram o lócus do estudo.

Como já dissemos, utilizamos, como guia, o método de investigação científico adotado pelo Projeto Atlas Linguístico do Brasil (Projeto ALiB). Esse método serviunos como base metodológica para a aplicação do questionário (QMS) a vinte informantes jovens, todos estudantes, de duas faixas etárias, de 18 a 40 anos (universitários) e de 13 a 15 anos (do ensino básico), localizáveis nas duas citadas instituições de ensino: na UNEMAT/Sinop, sendo quatro alunos do curso de Pedagogia e seis do curso de Letras, e na Escola Estadual Nossa Senhora da Glória (EENSG), dos quais cinco eram do $9^{\circ} \mathrm{A}$ e cinco do $9^{\circ} \mathrm{B}$. A opção por duas faixas etárias entre os estudantes compreendeu-se necessária para a realização de análise comparativa dos usos pronominais.

Além disso, fizemos, também, para todos os vinte informantes, a seguinte indagação: "Eu gostaria que você contasse um acontecimento marcante da sua vida", para a recolha do corpus narrativo. Esse corpus recolhido juntou-se ao corpus abstraído por Philippsen (2013) de narrativas livres que foram apreendidas de vinte pioneiros, com mais de 50 anos, das cidades de Vera, Santa Carmem, Sinop e Cláudia, que relataram suas experiências de migração, tendo sido a temática sugerida "a vinda e as dificuldades encontradas no início da colonização Norte mato-grossense ${ }^{2}$ ". Ressaltamos, aqui, que esse último corpus foi utilizado, neste artigo, tão somente para a verificação dos empregos pronominais em destaque.

Apresentaremos, a seguir, os resultados quantitativos dos usos pronominais de $e u$ e mim entre os estudantes e os pioneiros, na sequência, mostramos uma análise comparativa entre os usos de ambos, com o propósito de apreendermos o retrato de tais empregos pronominais no espaço geográfico em estudo, o Norte de Mato Grosso.

\footnotetext{
${ }^{2}$ Este corpus encontra-se publicado na íntegra em PHILIPPSEN, N. I. A constituição do léxico norte mato-grossense na perspectiva geolinguística: abordagens sócio-semântico-lexicais. Tese de Doutorado em Letras. São Paulo: Universidade de São Paulo, 2013.
} 


\subsection{Retrato de análise da questão 1/23: como os estudantes falam}

Convidamos o leitor, então, a acompanhar os resultados analíticos alcançados pelas considerações feitas aos dados, relativos especificamente à questão 23 presente no QMS do ALiB (2001), mas que podem ser ainda enriquecidos e implementados com o desenvolvimento de novas pesquisas na área.

A primeira questão do QMS (23), referente à classe dos pronomes, é Alguém pede para vocêlo(a)senhor(a) fazer uma tarefa. Mas outra pessoa acha que a tarefa era para ela. Então, vocêlo(a)senhor(a) diz: Essa tarefa, na verdade, é para___ fazer ${ }^{3}$. Por exemplo: a limpeza é para alguém fazer, a roupa é para outra pessoa lavar e a terceira tarefa (...) é para vocêlo(a)senhor(a). Como é vocêlo(a)senhor(a) diria?. Esta questão traz, como sugestões de resposta, os pronomes pessoais eu e mim. Cabe ressaltarmos que esta pergunta tem o intuito de verificar quais usos de pronomes são empregados antes de verbo no infinitivo.

A seguir trazemos a tabela pronominal, acompanhada de um cartograma, com os usos empreendidos pelos sujeitos estudantes, das duas faixas etárias, de 18 a 40 anos e de 13 a 15 anos; os dispositivos escolhidos para a apresentação dos dados objetivam facilitar a compreensão dos resultados e sua disposição diatópica, diageracional, diassexual e diastrática.

Tabela Pronominal 1/23 - 1

\begin{tabular}{|c|c|c|c|c|c|c|c|c|c|c|c|c|c|}
\hline Local & \multicolumn{4}{|c|}{ Unemat/Sinop } & \multicolumn{4}{|c|}{ Escola Alto da Glória } & \multicolumn{2}{|c|}{ Unemat/Sinop } & \multicolumn{3}{|c|}{ Escola A. da G. } \\
\hline Curso/Turma & \multicolumn{2}{|c|}{ Letras } & \multicolumn{2}{|c|}{ Pedagogia } & \multicolumn{2}{|c|}{ Turma A } & \multicolumn{2}{|c|}{ Turma B } & \multicolumn{2}{|c|}{ Subtotal } & \multicolumn{2}{|c|}{ Subtotal } & Total \\
\hline $\begin{array}{l}\text { Lexia } \\
\text { Sexo }\end{array}$ & M & $\mathbf{F}$ & M & $\mathbf{F}$ & M & $\mathbf{F}$ & M & $\mathbf{F}$ & M & $\mathbf{F}$ & M & $\mathbf{F}$ & \\
\hline Mim & 2 & 3 & 1 & 2 & 3 & 1 & 2 & 2 & 3 & 5 & 5 & 3 & 16 \\
\hline Eu & 1 & & 1 & & & 1 & & 1 & 2 & & & 2 & 04 \\
\hline TOTAL & 3 & 3 & 2 & 2 & 3 & 2 & 2 & 3 & 5 & 5 & 5 & 5 & 20 \\
\hline
\end{tabular}

Fonte Própria

\footnotetext{
${ }^{3} \mathrm{O}$ espaço em branco sugere que aqui deve ser dada uma resposta.
} 
Cartograma morfossintático Estudantes

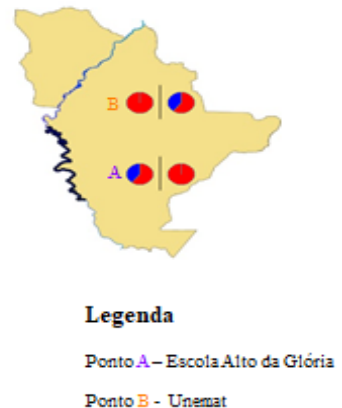

C $1 / 23$

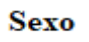

Eu/Mim

- MIM

EU

(1) (2)

1: $F$

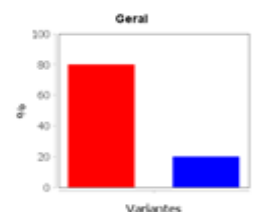

Fonte: Software Para Geração e Visualização de Cartas Linguísticas [JGVCLin] versão 1.1.

Conforme podemos observar na tabela e no cartograma, a preferência de uso pelos estudantes é do pronome mim, que foi proferido 16 vezes e encontra-se em uso pelos informantes das duas instituições de ensino localizadas em Sinop. Destacamos que, tanto na UNEMAT quanto na EENSG, 8 de 10 entrevistados aludiram ao pronome mim, sendo que há exatamente o mesmo número de respostas entre homens e mulheres, também 8.

Registramos, também, em menor proporção, o emprego do pronome $e u$, mais especificamente 4 manifestações, proferidas igualmente tanto na EENSG quanto na UNEMAT, com 2 registros em cada instituição e, de igual modo, ocorre sua distribuição entre homens e mulheres, ou seja, há 2 menções para cada sexo.

\subsection{Retrato de análise da questão 1/23: como os pioneiros falam}

Conforme já dissemos, valemo-nos das narrativas livres publicadas em Philippsen (2013) de vinte pioneiros, acima de 50 anos, que se encontram distribuídos pelas quatro cidades em foco, Vera, Sinop, Santa Carmem e Cláudia. Para tanto, utilizamo-nos dos temas sugeridos como respostas às questões relativas a pronomes que se encontram no QMS do AliB (2001) e procuramos localizá-los no corpo textual das narrativas. Destacamos, uma vez mais, que a questão 1/23 traz dois temas como sugestão: eu e mim, empregados antes do verbo no infinitivo 'fazer'. 
Compreendemos que, apesar dos resultados serem apenas uma pequena amostragem do falar desses pioneiros, são de suma importância como evidências científicas de como se apresenta o uso pronominal no Norte de Mato Grosso, visto que as narrativas se constituem como continuum da fala cotidiana, ou seja, representam a fala em seu estado natural e vernáculo regional.

$\mathrm{Na}$ tabela e cartograma que seguem, apresentamos os resultados alcançados sobre esses usos:

Tabela Pronominal 1/23 - 2

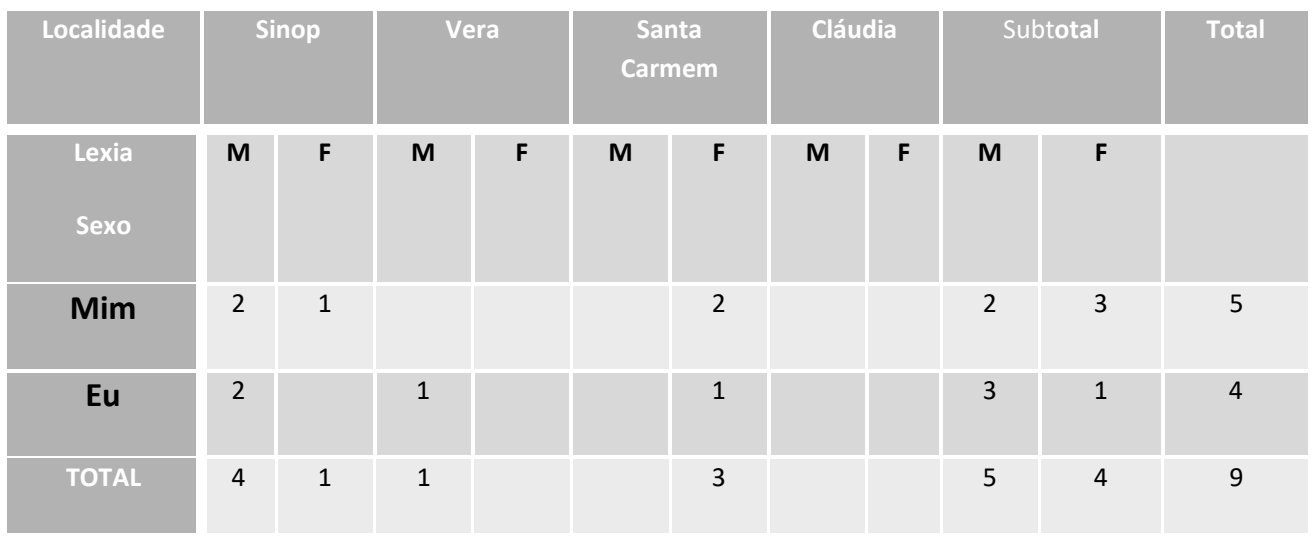

Fonte Própria

Catograma 1: usos pronominais de mim e eu entre os pioneiros

Cartograma morfossintático
Pioneiros

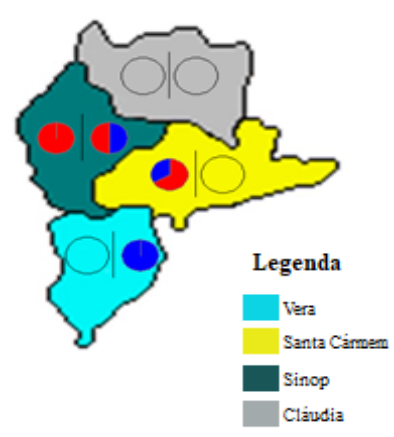

C $1 / 23$

Sexo

$\mathbf{E u} / \mathbf{M i m}$

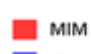

(1) (2)

1:F

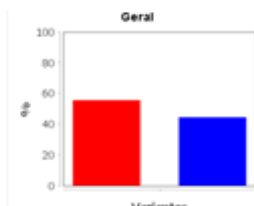

Fonte: Software Para Geração e Visualização de Cartas Linguísticas [JGVCLin] versão 1.1. 
Os dados mostram que o pronome mim é o de maior ocorrência no corpo textual das narrativas livres, com 5 informantes que o utilizam, ainda que só tenha sido proferido em duas das quatro cidades pesquisadas, Sinop e Santa Carmem. Nesse contexto, destacamos um número maior de mulheres que o usam, 3 contra 2 homens.

Já o pronome eu exprime 4 ocorrências em três dos quatro pontos de inquérito, Sinop, Vera e Santa Carmem, sendo apreendido em 4 informantes masculinos e apenas 1 feminino.

\subsection{Alinhavos de interseção da questão 1/23: as escolhas pronominais de pioneiros $e$ estudantes}

Como já enfatizado, o propósito maior deste estudo é apresentar a efígie do falar pronominal que se empreende entre os usos de informantes mais velhos, pioneiros acima de 50 anos, e de informantes mais jovens, estudantes, que foram divididos em duas faixas etárias, de 13 a 15 anos (do ensino básico) e de 18 a 40 anos (universitários).

A seguir, de forma ainda mais especificada, apresentamos os resultados comparativos dos usos pronominais entre pioneiros e estudantes.

\subsection{Pronomes pessoais: usos de eu e mim antes de verbo no infinitivo}

Inicialmente, vamos apresentar aqui os dados ainda mais específicos dos usos de $e u$ e, na sequência, de mim. Para esta especificidade, valemo-nos somente dos textos narrativos, ou seja, dos textos transcritos que foram apreendidos da indagação "Eu gostaria que você contasse um acontecimento marcante da sua vida"; salientamos que todos os vinte estudantes (dez do ensino básico e dez universitários) relataram-nos um ou mais acontecimentos e, dessa forma, enriqueceram nossos corpora. Além desses textos narrativos, também utilizamos as narrativas livres de vinte pioneiros do Norte de Mato Grosso transcritas por Philippsen (2013). Após a leitura minuciosa deste material, elaboramos quadros para nos auxiliarem na análise dos dados.

Reiteramos, também, que as dimensões observadas foram a diatópica, a diageracional, a diassexual, a diastrática e a diafásica. A ordem de apresentação seguirá 
a seguinte disposição:

a) quadro de resultados e contextualização dos estudantes;

b) quadro de resultados e contextualização dos pioneiros;

c) considerações analíticas comparativas.

Com relação à legenda dos quadros, evidenciamos que UL refere-se a universitário de Letras, UP a universitário de Pedagogia e a abreviação das cidades nas quais os pioneiros residem ${ }^{4}$ são, respectivamente, $\mathbf{V}$ (Vera), SC (Santa Carmem) e $\mathbf{S}$ (Sinop). Quanto ao número de ocorrências que foram expressas nos quadros, esclarecemos que se referem ao total de vezes que apareceram no corpus de um mesmo informante, isto é, ao total de vezes que o informante, em sua narrativa, utilizou eu e/ou mim antes de verbos no infinitivo. A sequência da apresentação traz primeiro os resultados dos usos de eu e, em seguida, dos usos de mim.

\section{1) Usos do pronome $e u$ antes de verbos no infinitivo:}

Quadro 1: ocorrências entre os estudantes

\begin{tabular}{|c|c|c|c|c|c|c|}
\hline $\begin{array}{c}\mathbf{N}^{\mathbf{o}} \\
\text { ocorrência }\end{array}$ & Cidade & Informante & Sexo & Idade & Escolaridade & Naturalidade \\
\hline 1 & Sinop & UP1 & feminino & 18 anos & $\begin{array}{l}1^{\circ} \text { semestre } \\
\text { Pedagogia } \\
\text { (cursando) }\end{array}$ & $\begin{array}{l}\text { Guarantã do } \\
\text { Norte - MT }\end{array}$ \\
\hline 1 & Sinop & UL2 & $\begin{array}{l}\text { masculin } \\
\mathrm{o}\end{array}$ & 18 anos & $\begin{array}{l}1^{\circ} \text { semestre } \\
\text { Letras } \\
\text { (cursando) }\end{array}$ & Santa Inês - MA \\
\hline 1 & Sinop & UL8 & $\begin{array}{l}\text { masculin } \\
\mathrm{o}\end{array}$ & 20 anos & $\begin{array}{l}1^{\circ} \text { semestre } \\
\text { Letras } \\
\text { (cursando) }\end{array}$ & Medianeira - PR \\
\hline 2 & Sinop & UL9 & feminino & 28 anos & $\begin{array}{l}1^{\circ} \text { semestre } \\
\text { Letras } \\
\text { (cursando) }\end{array}$ & $\begin{array}{l}\text { Marcelândia - } \\
\text { MT }\end{array}$ \\
\hline Total $=5$ & & & & & & \\
\hline
\end{tabular}

Fonte: própria

\footnotetext{
${ }^{4}$ Cabe especificar que não encontramos, nas narrativas dos pioneiros da cidade de Cláudia, nenhum dos dois usos pronominais em análise neste artigo. 
Quadro 2: ocorrências entre os pioneiros

\begin{tabular}{|c|c|c|c|c|c|c|}
\hline $\mathbf{N}^{\mathbf{0}}$ ocorrência & Cidade & Informante & Sexo & Idade & Escolaridade & Naturalidade \\
\hline 2 & Vera & V3 & masculino & $\begin{array}{l}78 \\
\text { anos }\end{array}$ & $\begin{array}{l}3^{\mathrm{a}} \text { série do } \\
\mathrm{EF}^{5}\end{array}$ & $\mathrm{SC}$ \\
\hline 1 & $\begin{array}{l}\text { Santa } \\
\text { Carmem }\end{array}$ & SC6 & feminino & $\begin{array}{l}68 \\
\text { anos }\end{array}$ & $\begin{array}{l}2^{a} \text { série do } \\
\text { EF (EJA) }\end{array}$ & Aracaju -SE \\
\hline 1 & Sinop & S10 & masculino & $\begin{array}{l}54 \\
\text { anos }\end{array}$ & $\begin{array}{l}8^{\mathrm{a}} \text { série do } \\
\mathrm{EF}\end{array}$ & Guabiju - RS \\
\hline 3 & Sinop & S12 & masculino & $\begin{array}{l}63 \\
\text { anos }\end{array}$ & $\begin{array}{l}4^{\text {a }} \text { série do } \\
\mathrm{EF}\end{array}$ & $\mathrm{SC}$ \\
\hline Total $=7$ & & & & & & \\
\hline
\end{tabular}

Fonte Própria

Conforme os dados dos quadros, podemos observar, comparativamente, que há 7 ocorrências de uso do pronome $e u$ antes de verbo no infinitivo entre os pioneiros, acima de 50 anos, sendo 6 de informantes masculinos e apenas 1 menção feminina foi feita, da informante SC6 residente na cidade de Santa Carmem; já entre os estudantes, há 5 ocorrências desse uso nas narrativas livres coletadas, 3 realizadas por mulheres e 2 por homens, sendo todos os sujeitos da faixa etária de 18 a 40 anos e universitários.

\footnotetext{
${ }^{5} \mathrm{EF}=$ Ensino Fundamental.
} 


\section{2) Usos do pronome mim antes de verbos no infinitivo:}

Quadro 3: ocorrências entre os estudantes

\begin{tabular}{|c|c|c|c|c|c|c|}
\hline $\mathbf{N}^{0}$ ocorrência & Cidade & Informante & Sexo & Idade & Escolaridade & Naturalidade \\
\hline 2 & Sinop & E7 & feminino & $\begin{array}{l}14 \\
\text { anos }\end{array}$ & $\begin{array}{l}9^{\circ} \text { ano do EF } \\
\text { (cursando) }\end{array}$ & Sinop - MT \\
\hline 1 & Sinop & E10 & feminino & $\begin{array}{l}15 \\
\text { anos }\end{array}$ & $\begin{array}{l}9^{\circ} \text { ano do EF } \\
\text { (cursando) }\end{array}$ & Sinop - MT \\
\hline 1 & Sinop & UL2 & masculino & $\begin{array}{l}18 \\
\text { anos }\end{array}$ & $\begin{array}{l}1^{\circ} \text { semestre } \\
\text { Letras } \\
\text { (cursando) }\end{array}$ & $\begin{array}{l}\text { Santa Inês - } \\
\text { MA }\end{array}$ \\
\hline 2 & Sinop & UP7 & feminino & $\begin{array}{l}26 \\
\text { anos }\end{array}$ & $\begin{array}{l}1^{\circ} \text { semestre } \\
\text { Pedagogia } \\
\text { (cursando) }\end{array}$ & $\begin{array}{l}\text { Diamantino - } \\
\text { MT }\end{array}$ \\
\hline 6 & Sinop & UL9 & feminino & $\begin{array}{l}28 \\
\text { anos }\end{array}$ & $\begin{array}{l}1^{\circ} \text { semestre } \\
\text { Letras } \\
\text { (cursando) }\end{array}$ & $\begin{array}{l}\text { Marcelândia - } \\
\text { MT }\end{array}$ \\
\hline 1 & Sinop & UP10 & masculino & $\begin{array}{l}20 \\
\text { anos }\end{array}$ & $\begin{array}{l}1^{\circ} \text { semestre } \\
\text { Pedagogia } \\
\text { (cursando) }\end{array}$ & Juína- MT \\
\hline
\end{tabular}

Fonte Própria

Quadro 4: ocorrências entre os pioneiros

\begin{tabular}{|c|c|c|c|c|c|c|}
\hline $\mathbf{N}^{\mathbf{o}}$ ocorrência & Cidade & Informante & Sexo & Idade & Escolaridade & Naturalidade \\
\hline 1 & $\begin{array}{l}\text { Santa } \\
\text { Carmem }\end{array}$ & SC6 & feminino & $\begin{array}{l}68 \\
\text { anos }\end{array}$ & $\begin{array}{l}2^{\mathrm{a}} \text { série do EF } \\
\text { (EJA) }\end{array}$ & Aracaju -SE \\
\hline 3 & $\begin{array}{l}\text { Santa } \\
\text { Carmem }\end{array}$ & SC8 & feminino & $\begin{array}{l}66 \\
\text { anos }\end{array}$ & $\begin{array}{l}3^{\mathrm{a}} \text { série do EF } \\
(\mathrm{EJA})\end{array}$ & $\begin{array}{l}\text { Misericórdia de } \\
\text { Piancó - PB }\end{array}$ \\
\hline 3 & Sinop & S10 & masculino & $\begin{array}{l}54 \\
\text { anos }\end{array}$ & $\begin{array}{l}8^{\text {a }} \text { série do } \\
\mathrm{EF}\end{array}$ & Guabiju - RS \\
\hline 1 & Sinop & S12 & masculino & $\begin{array}{l}63 \\
\text { anos }\end{array}$ & $\begin{array}{l}4^{\text {a }} \text { série do } \\
E F\end{array}$ & $\mathrm{SC}$ \\
\hline 2 & Sinop & S13 & feminino & $\begin{array}{l}63 \\
\text { anos }\end{array}$ & $\begin{array}{l}5^{\text {a }} \text { série do } \\
E F\end{array}$ & Giruá - RS \\
\hline Total $=10$ & & & & & & \\
\hline
\end{tabular}

Fonte: própria

Revista Moara, n. 54, ago-dez 2019 ISSN: 0104-0944

Recebido em 02/08/2019

Avaliado em 04/12/2019 
De acordo com os dados dos quadros, verificamos que há 10 ocorrências de uso do pronome mim antes de verbo no infinitivo entre os pioneiros, acima de 50 anos, sendo 6 de informantes femininas e 4 menções masculinas; observamos, ainda, que esses empregos são realizados apenas nas cidades de Sinop e de Santa Carmem. Entre os estudantes, encontramos 13 ocorrências no corpus, 9 realizadas por mulheres e 4 por homens; cabe ressaltar, ainda, que 6 sujeitos estudantes fizeram uso desta forma pronominal, sendo 2 estudantes do ensino básico e 4 universitários.

\subsubsection{Considerações analíticas comparativas entre os usos de eu e mim antes de verbo no infinitivo}

Conforme os resultados numéricos anteriormente verificados, podemos fazer algumas considerações analíticas sobre como se encontram os usos pronominais de eu e mim antes de verbo no infinitivo no Norte de Mato Grosso. Nesse contexto, encontramos um uso maior do pronome mim, com 23 ocorrências expressas por 11 distintos informantes, dentre os quais se evidenciam 4 mulheres estudantes e 3 pioneiras, já entre os informantes masculinos, o número é o mesmo entre os pioneiros e estudantes, 2 de cada segmento. Todavia, apenas encontramos esse uso em duas cidades lócus da pesquisa, Sinop, com 6 menções, e Santa Carmem, com 4. Com relação às instituições de ensino, localizamos o uso deste pronome em ambas, tendo sido produzido por 2 alunos da EENSG e por 4 da UNEMAT.

Sendo assim, temos como resultados que, dentre os informantes, mais mulheres utilizam a forma pronominal mim, 7, e mais alunos da UNEMAT, 4. Cabe frisarmos, contudo, que este uso não-padrão, para os preceitos gramaticais normativos, não é recente; já em 1872, Visconde de Taunay faz uso desta forma em seu romance Inocência, mas, em nota de rodapé explica que "É este erro comum no interior de todo o Brasil, sobretudo na província de São Paulo, onde pessoas até ilustradas nele incorrem com frequência". Vale ressaltarmos aqui que, se registrado por este autor em uma obra literária neste ano do século XIX, este uso certamente já acontecia bem antes deste período. 
Esta construção sintática, portanto, taxada como erro por Taunay, já vem de longa data, e, conforme Bagno:

\begin{abstract}
Até pouco tempo atrás, essa construção era muito estigmatizada pelos mais letrados, tida como própria dos falantes menos escolarizados ou sem qualquer escolarização, habitantes da zona rural ou das periferias marginalizadas das grandes cidades. Ora, hoje é possível afirmar que ela é empregada pela ampla maioria da população, incluindo membros das antigas e das novas classes médias. A condenação unânime dos defensores da TGP ${ }^{6}$ serviu de barragem a essa sintaxe durante longo período de nossa história em que a fala urbana de prestígio era restrita a uma parcela muito reduzida da população. Mas o que vai ocorrer a partir de agora? (BAGNO, 2011, p. 498-499).
\end{abstract}

Na sequência desse questionamento, o próprio autor o responde dizendo que a barragem a esse uso sintático já foi rompida na língua falada, pois é assim que se expressa oralmente a maioria da população, incluindo pessoas altamente escolarizadas, como médicos, engenheiros, economistas, professores (inclusive de português) etc. Por sua vez, a repressão ainda vigora com sucesso em gêneros textuais mais monitorados, tais como teses, dissertações, resenhas escolares, que são o último reduto das formas linguísticas canonizadas na tradição normativa. Ainda segundo Bagno (2007), essa resistência vai depender da dinâmica social, sendo possível que, em breve, pode não provocar mais a rejeição dos falantes urbanos mais letrados e então se tornar um traço gradual, ou seja, uma forma de uso da língua que está presente na fala de todos os brasileiros, desde os mais pobres e analfabetos até os mais ricos e altamente escolarizados.

Já o uso normativo de $e u$ + verbo no infinitivo foi trazido no corpo das narrativas 12 vezes, sendo expressas por 8 informantes diferentes, dentre os quais se destacam 2 mulheres estudantes e apenas 1 pioneira; já entre os informantes masculinos temos 3 pioneiros e 2 estudantes. Os pioneiros que utilizaram essa forma são localizáveis nas cidades de Vera (2 ocorrências), Santa Carmem (1 ocorrência) e Sinop (4 ocorrências). Com relação às instituições de ensino, localizamos o uso deste pronome somente na UNEMAT, tendo sido proferido 5 vezes, por 1 estudante que frequenta o curso de Pedagogia e 3 de Letras.

Esses dados nos revelam, por sua vez, resultados que destacam maior uso evidenciado entre os homens pioneiros, todos com pouca escolarização: $3^{\mathrm{a}}$ série do EF, 4

\footnotetext{
${ }^{6}$ TGP $=$ Tradição Gramatical do Português.
} 
${ }^{a}$ série do EF e 8 a série do EF. Por outro lado, entre os estudantes, destacamos o maior uso entre os mais escolarizados, ou seja, os universitários, ainda que tenhamos tido duas respostas de eu na EENSG no momento em que aplicamos o QMS.

\subsection{Costuras analíticas entre os fatores extralinguísticos}

Conforme dissemos já na Introdução deste artigo, mobilizamos, no decorrer da pesquisa, as variáveis extralinguísticas diassexual, que é a comparação entre a fala dos homens e a das mulheres; a diastrática, que faz referência ao grau de instrução/escolaridade; a diafásica, que é a que contempla atos de fala vinculados ao momento de realização, no caso específico deste estudo, as narrativas livres, a diageracional, que se refere à idade dos informantes e às possíveis divergências entre o falar dos jovens e idosos, e a diatópica, que, neste estudo, mobilizou quatro pontos de inquérito, ou seja, quatro distintas cidades e duas diferentes instituições de ensino.

Quanto aos resultados relacionados à dimensão diafásica, destacamos que, das narrativas livres e das respostas à questão 23 do QMS do AliB, apreendidas mais especificamente em Sinop, Santa Carmem, na UNEMAT e na EENSG, as realizações concretas de maior utilização foram do pronome mim, com 39 ocorrências realizadas pelos informantes das três faixas etárias em análise. Para o cálculo apresentado, somamos todas as ocorrências, ou seja, todas as menções feitas nas narrativas livres e as manifestadas pelos estudantes nas respostas do QMS.

Com relação à dimensão diatópica, apresentamos abaixo os resultados obtidos com a catalogação dos dados referentes aos quatro pontos de inquérito e às duas instituições de ensino lócus da pesquisa:

\begin{tabular}{|c|c|c|c|c|c|c|c|c|c|c|c|c|c|c|}
\hline \multicolumn{15}{|c|}{ Dimensão diatópica: } \\
\hline $\begin{array}{l}\text { Pontos/ } \\
\text { Instituições }\end{array}$ & & Vera & & $\begin{array}{l}\text { Santa } \\
\text { Carmem }\end{array}$ & & Sinop & & Cláudia & & Escola & & UNEMAT & & Total \\
\hline Variantes & № & $\%$ & № & $\%$ & № & $\%$ & № & $\%$ & № & $\%$ & № & $\%$ & № & $\%$ \\
\hline Eu & 2 & $100,00 \%$ & 1 & $20,00 \%$ & 4 & $40,00 \%$ & 0 & $0,00 \%$ & 2 & $15,38 \%$ & 7 & $28,00 \%$ & 16 & $29,09 \%$ \\
\hline Mim & 0 & $0,00 \%$ & 4 & $80,00 \%$ & 6 & $60,00 \%$ & 0 & $0,00 \%$ & 11 & $84,62 \%$ & 18 & $72,00 \%$ & 39 & $70,91 \%$ \\
\hline Total & 2 & $100,00 \%$ & 5 & $100,00 \%$ & 10 & $100,00 \%$ & 0 & $0,00 \%$ & 13 & $100,00 \%$ & 25 & $100,00 \%$ & 55 & $100,00 \%$ \\
\hline
\end{tabular}

Fonte Própria 
Os resultados da dimensão diastrática (escolaridade), disponibilizados na sequência, foram especificados da seguinte forma: Ensino Fundamental Anos Iniciais (EFAI), para os informantes dos cinco primeiros anos do Ensino Fundamental, incompleto ou concluído; Ensino Fundamental Anos Finais (EFAF), para os informantes dos quatro anos finais do Ensino Fundamental, incompleto ou concluído; Ensino Médio (EM), incompleto ou concluído, e Ensino Superior (ES), incompleto ou concluído.

Dimensão diastrática:

\begin{tabular}{|l|l|l|l|l|l|l|l|l|l|l|}
\hline Escolaridade & & EFAI & & EFAF & & EM & & ES & & Total \\
\hline Variantes & № & $\%$ & № & $\%$ & № & $\%$ & № & $\%$ & № & $\%$ \\
\hline Eu & 3 & $42,86 \%$ & 3 & $25,00 \%$ & 0 & $0,00 \%$ & 11 & $57,89 \%$ & 17 & $44,74 \%$ \\
\hline Mim & 4 & $57,14 \%$ & 9 & $75,00 \%$ & 0 & $0,00 \%$ & 8 & $42,11 \%$ & 21 & $55,26 \%$ \\
\hline Total & 5 & $100,00 \%$ & 6 & $100,00 \%$ & 0 & $0,00 \%$ & 4 & $100,00 \%$ & 73 & $100,00 \%$ \\
\hline
\end{tabular}

Fonte Própria

A seguir, mostramos os resultados da dimensão diageracional, que apresenta três distintas faixas etárias: acima de 50 anos, de 18 a 40 anos e de 13 a 15 anos.

Dimensão diageracional:

\begin{tabular}{|c|c|c|c|c|c|c|c|c|}
\hline $\begin{array}{c}\text { Faixas } \\
\text { etárias }\end{array}$ & $\begin{array}{c}\text { Acima } \\
\text { de } 50 \\
\text { anos }\end{array}$ & $\begin{array}{c}18 \text { a } 40 \\
\text { anos }\end{array}$ & $\begin{array}{c}13 \text { a } 15 \\
\text { anos }\end{array}$ & Total \\
\hline Variantes & № & $\%$ & № & $\%$ & № & $\%$ & № & $\%$ \\
\hline Eu & 4 & $44,44 \%$ & 6 & $42,86 \%$ & 2 & $20,00 \%$ & 12 & $36,36 \%$ \\
\hline Mim & 5 & $55,56 \%$ & 8 & $57,14 \%$ & 8 & $80,00 \%$ & 21 & $63,64 \%$ \\
\hline Total & 9 & $100,00 \%$ & 14 & $100,00 \%$ & 10 & $100,00 \%$ & 33 & $100,00 \%$ \\
\hline
\end{tabular}


Finalmente, apresentamos os resultados da dimensão diassexual que se evidenciam entre os sexos masculino e feminino na região norte de Mato Grosso, que são os seguintes:

\section{Dimensão diassexual:}

\begin{tabular}{|c|c|c|c|c|c|c|}
\hline Sexo & & Masculino & & Feminino & & Total \\
\hline Variantes & $\mathrm{N}^{\mathbf{o}}$ & $\%$ & $\mathrm{~N}^{\mathbf{o}}$ & $\%$ & $\mathrm{~N}^{\mathbf{o}}$ & $\%$ \\
\hline $\mathrm{Eu}$ & 5 & $31,25 \%$ & 3 & $23,08 \%$ & 8 & $27,59 \%$ \\
\hline $\mathrm{Mim}$ & 11 & $68,75 \%$ & 10 & $76,92 \%$ & 21 & $72,41 \%$ \\
\hline Total & 16 & $100,00 \%$ & 13 & $100,00 \%$ & 29 & $100,00 \%$ \\
\hline
\end{tabular}

Fonte: Própria

Após todos esses apontamentos feitos, e sem deixar de realçar as possibilidades outras de leituras ainda possíveis, compreendemos que atingimos os objetivos de mostrar um pequeno recorte de como o falar no nível morfossintático da região Norte mato-grossense se apresenta e está em constituição; tais resultados, por sua vez, encontram-se inter-relacionados com os idioletos trazidos pelos pioneiros de seus estados de origem e, conforme Coseriu (1979), do próprio 'sistema de possibilidades', ou seja, das tendências próprias do sistema linguístico e normativo que o fazem ser vivo, complexo, flexível e contínuo.

\section{Considerações Finais}

As reflexões analíticas feitas objetivaram, fundamentalmente, mostrar como se apresentam os usos pronominais de $e u$ e mim no falar norte mato-grossense, a partir da realização do estudo com fundamentos da Dialetologia Pluridimensional e Relacional. Buscamos, além de mostrar essas realizações pronominais no falar da região em foco, trazer subsídios que possam contribuir para ampliar a base de dados do Projeto Atlas Linguístico do Brasil. 
Após todos os apontamentos feitos, e sem deixar de realçar as possibilidades outras de leituras ainda possíveis, compreendemos que atingimos os objetivos de mostrar um pequeno recorte de como o falar no nível morfossintático dessas formas se apresenta e está em constituição nessa região de ocupação recente; que implicações de natureza sociocultural influenciaram na formação e na expansão desses usos pronominais, implicações essas que podem ser resumidas a partir da junção de todos os idioletos trazidos pelos pioneiros de seus estados de origem e, conforme Coseriu (1979), do próprio 'sistema de possibilidades', ou seja, das tendências próprias do sistema linguístico e normativo que o fazem ser vivo, complexo, flexível e contínuo.

Todas essas reflexões tecidas, por sua vez, vêm ao encontro das ponderações de Isquerdo, quando diz que:

$\mathrm{Na}$ verdade, essa norma foi se desenhando de forma distinta nas diferentes regiões brasileiras, motivada por condicionantes extralinguísticos, como os fatores físico-geográficos que as individualizam, os contatos étnicos que ali se processaram, as atividades econômicas predominantes, enfim, pela história social das várias áreas culturais que foram se formando, nos mais diferentes rincões do Brasil, ao longo da sua história. (ISQUERDO, 2006, p.18).

Com esses resultados alcançados e apresentados neste estudo, pretendemos cooperar qualitativamente com a incipiente pesquisa realizada na região norte matogrossense, em especial com os projetos de pesquisa desenvolvidos pela Universidade Estadual de Mato Grosso - UNEMAT.

Como possível contribuição ao acervo científico já existente, portanto, oferecemos aos estudiosos da língua portuguesa, aos professores, aos dialetólogos, aos gramáticos e aos interessados em pesquisas linguísticas/dialetológicas um estudo descritivo, interpretativo e reflexivo dos usos pronominais de eu e mim existentes nesta região para que possa ser cotejado com outros falares de outras regiões do país, ou, ainda, comparado com dados apreendidos futuramente neste mesmo espaço geográfico. 


\section{REFERÊNCIAS}

BAGNO, M. Nada na língua é por acaso: por uma pedagogia da variação linguística. São Paulo: Parábola Editorial, 2007.

Gramática pedagógica do português brasileiro. São Paulo: Parábola Editorial, 2011.

COMITÊ NACIONAL DO PROJETO ALiB. Atlas linguístico do Brasil: questionário 2001. Londrina: Ed. UEL, 2001.

COSERIU, E. A. Sincronia, diacronia e história: o problema da mudança linguística. Trad. Carlos Alberto da Fonseca e Mário Ferreira. São Paulo: Presença, 1979.

Competencia lingüística: elementos de la teoria del hablar. Madrid: Gredos, 1992.

ILARI, R.; BASSO, R. O português da gente: a língua que estudamos e a língua que falamos. São Paulo: Contexto, 2006.

ISQUERDO, A. N. Achegas para a discussão do conceito de regionalismos no português do Brasil. Alfa, São Paulo, 50 (2): 9-24, 2006.

PHILIPPSEN, N. I. A constituição do léxico norte mato-grossense na perspectiva geolinguística: abordagens sócio-semântico-lexicais. Tese de Doutorado em Letras. São Paulo: Universidade de São Paulo, 2013.

RADTKE, Edgar. THUN, Harald (org.). Neue Wege der Romanischen Geolingyistik. Westense - Verl. 1996. p. 210-274. 
THUN, H. A Dialetologia pluridimensional no Rio da Prata. In: STAHLZIWS, Ana Maria. Estudos de Variação Linguística no Brasil e no Cone Sul. Porto Alegre: UFGRS, 2005, p.63-92. 